\title{
Assessing Pediculosis infection and cofactors among 8-10-year-old Female students in Bushehr province, Iran
}

\author{
Research Article
}

\begin{abstract}
Ali Asadian1, Adel Moqadas², Mahmood Mahbobi Rad³, Ahmad Sotoudeh4*, Mojtaba Fattahi Ardakanis
\end{abstract}

1. PhD Candidate in Health Education and Health Promotion, International Campus, Shahid Sadoughi University of Medical Sciences, Yazd, Iran.

2. Department of Public Health, Bushehr University of Medical Sciences, Bushehr, Iran.

3. PhD Candidate in Health Education and Health promotion. Department of Health Education and Health Promotion, School of Public Health, Rafsanjan University of Medical Sciences, Rafsanjan, Iran.

4. PhD Candidate in Health Education and Health promotion. Department of Public Health,

School of Public Health, Bushehr University of Medical Sciences, Bushehr, Iran.

5. PhD in Health Education and Health Promotion, Yazd Diabetes Research Center, Shahid Sadoughi University of Medical Sciences, Yazd, Iran.

\begin{abstract}
Introduction: Lice are widespread at a global scale and afflict all socioeconomic classes. Despite advanced healthcare, head lice are particularly prevalent among elementary school female students. Thus, the present research aims to explore pediculosis infection and its cofactors among 8-10-year-old female students in Jam County, Bushehr province, Iran, in 2019. Methodology: The present descriptive research was analytical in type. The research population comprised female elementary school students in Jam County, selected through multi-stage randomization. The final sample selected consisted of 854 participants. The data collection instruments were a questionnaire and an optic test of all students at school. SPSS 22 was used to statistically analyze the data via Chi-square test and multivariate logistic regression analysis. The significance level was set at $<0.05$. Findings: The mean age of the participating students was 9.5 years. The prevalence of head lice among this sample was $15.4 \%$ and was higher in urban areas than the rural. Statistically significant correlations were found between lice infection and variables including father's occupation and education, mother's occupation and education and having a bathroom at home $(p<0.05)$. Conclusion: The prevalence of lice in the present research showed to be higher that a body of related literature. Thus, it is essential to make preventive interventions to diagnose, treat and control pediculosis and consider the infection-related cofactors of lice infection in healthcare centers.
\end{abstract}

Key Words: Pediculosis, Schools, Jam county.

\section{Introduction}

Head lice is the most prevalent lice especially in 8-10-year-old school students and the infection rate is higher among female students than the male (1). As the related literature showed, despite the existing attempts to control the disease, this disease has not yet been controlled in different countries to an acceptable extent and is still on the rise. The pediculosis cases are estimates to exceed hundreds of million worldwide (2).

Head lice is not confined to the third-world countries only and afflicts advanced industrial countries too. As it has been reported, pediculosis is more prevalent among American students than any other contagious disease (3). Head lice are easily transmitted

* Corresponding Author:

Ahmad Sotoudeh

Department of Public Health,

School of Public Health,

Bushehr University of Medical Sciences,

Bushehr, Iran

Email Id: sotoudeh ahmad@yahoo.com directly while children are playing or indirectly through sharing such devices as hairbrush, clothes, hair comb and even sharing wardrobes, public seats (e.g. on a public means of transport) especially in crowded places such as dormitories, schools, kindergartens and prisons. Factors such as improper state of health, resistance to insecticides, low socioeconomic status and medical failure can increase the prevalence of lice $(2,4)$. Moreover, lice infection can be transmitted from school children to families (4). The prevalence of pediculosis varies across seasons, yet has been observed to be the highest in summer and early autumn (5). The best way against lice infection is a combined effect of medications and environmental factors. Thus, using Lindane shampoo and permethrin is recommended for those infected along with public education provided to empower all people to promote health in societies (6). In American context, the infection has been reported to prevail among $25 \%$ of school students (2). The prevalence of lice infection was reported to be $13.6 \%$ in Mexico (7). According to the National Pediculosis Association in America, head infection of more than 5\% has been considered endemic (8). In Thailand, the 
prevalence of lice was reported to be $23.32 \%$ (9). In Iran, the percentage ranges between $1.6-13.4 \%$ in different areas (10). In a systematic meta-analysis in Iran in 2016 among elementary schools, the prevalence of lice was found to be $6.1 \%$ and $8.8 \%$ among boys and girls, respectively (11). As a body of research showed, the prevalence of the infection is $4 \%$ I Urmia, $13.5 \%$ in Hamedan, $1.8 \%$ in Kerman and $4.7 \%$ in Sanandaj (12-13). A body of related literature in Iran about lice infection indicated a high prevalence among school students (11). Today, despite advanced medical sciences and promoted state of health, insect infection especially ectoparasites still threaten public health. Not only do head lice affect the health system, but they also damage students psychologically and academically and thus cause social concerns followed by social and political concerns (14).

Considering the adverse effects of lice on health and mentality and the essentiality of controlling the disease, the present research aimed to explore pediculosis infection and its cofactors among 7-10-yearold female students in Jam County, Bushehr Province, Iran in 2019.

\section{Methodology}

The present descriptive research was analytical in type. The target population comprised 8-10-year-old female students living in Jam County. The sample was selected through multi-stage randomization. The inclusion criteria were attending the introduction session, parents' signed informed consent and head examination. Absence at the introduction session and unwillingness to take part in the research were the exclusion criteria. The sample consisted of 490 urban and 364 rural residents. The required data were collected through questionnaires as well as the head examination of students.

The data collection instrument was a 20 -item questionnaire with demographic content (student's age, grade of school, father's education and occupation, mother's education and occupation) plus items exploring personal and familial behaviors. To determine the prevalence of infection, head examination and parasite sampling were used. The validity of the questionnaire was checked and confirmed by a panel of experts. The reliability of the instrument was tested on 30 students similar to the main research participants in all aspects.

Questionnaire completion was done by the researcher as well as school health educators through directly interviewing students individually. To distinguish the infected, the head and hair of all students were examined. The examination involved a close observation of hair and head especially in the back of head and back of ears by a well-trained female expert using a magnifier. Diagnosis with infection was marked by the observation of live eggs, immature and mature lice according to the existing standards (the booklet on preventing lice published by Iran Ministry of health distributed at schools). The hair was examined closely (especially behind ears and upper neck) in light for 4

minutes. Upon diagnosis, the student was sent to the local healthcare center for treatment.

Participation in the research was completely voluntary. Once the purpose of research was explained to parents, they were asked to provide an informed consent. The participants were ensured of the confidentiality of the information they provided. Their participation was entirely voluntary and the results were published without individual identification. When the questionnaires were completed by students, the data analysis was done in SPSS22 using Chi-square test and logistic regression analysis. The significance level was set at 0.05 .

\section{Findings}

As the results showed, the mean age of the participants was 9.5 years. 305 students (35.71\%) studied at the $4^{\text {th }}$ grade of elementary school. The highest frequency was $336(39.34 \%)$ comprising the 10year age group. 490 students $(57.37 \%)$ resided in urban areas and $364(42.62 \%)$ in rural areas. A total number of 766 students $(89.69 \%)$ studied at public schools while 88 students $(10.30 \%)$ at private schools. As for father's education, 301 students $(35.24 \%)$ had a high school degree. The majority of mothers $(n=384,40.74 \%)$ also had a high school degree. Concerning father's occupation, the majority $(n=396,46.37 \%)$ worked freelance and for mother's occupation, the majority $(\mathrm{n}=605,70.84 \%)$ were housewives. A total number of 187 participants $(21.86 \%)$ had a history of lice infection. 79 participants $(9.2 \%)$ were found with instances of lice infection among family members.

Table 1: Distribution of demographic features among research participants

\begin{tabular}{|c|c|c|c|}
\hline Variable & & & $\%$ \\
\hline \multirow[t]{3}{*}{ Grade of school } & $2^{\text {nd }}$ grade & 254 & 28.68 \\
\hline & $3^{\text {rd }}$ grade & 295 & 34.54 \\
\hline & $4^{\text {th }}$ grade & 305 & 35.71 \\
\hline \multirow[t]{3}{*}{ Age } & 8 years & 336 & 39.34 \\
\hline & 9 years & 275 & 32.20 \\
\hline & 10 years & 243 & 28.45 \\
\hline \multirow[t]{2}{*}{ Place of residence } & Urban & 490 & 57.37 \\
\hline & Rural & 364 & 42.62 \\
\hline \multirow[t]{2}{*}{ Type of school } & Public & 766 & 89.69 \\
\hline & private & 88 & 10.30 \\
\hline \multirow[t]{4}{*}{ Father's education } & Uneducated & 32 & 3.74 \\
\hline & Elementary school & 125 & 14.63 \\
\hline & Junior high school & 149 & 17.44 \\
\hline & High school & 301 & 35.24 \\
\hline \multirow[t]{4}{*}{ Mother's education } & Uneducated & 39 & 4.56 \\
\hline & Elementary school & 114 & 13.34 \\
\hline & Junior high school & 152 & 17.79 \\
\hline & High school & 348 & 40.74 \\
\hline \multirow[t]{3}{*}{ Father's occupation } & Office work & 117 & 13.70 \\
\hline & Labor work & 297 & 34.77 \\
\hline & Army & 44 & 5.1 \\
\hline \multirow[t]{3}{*}{ Mother's occupation } & Housewife & 605 & 70.84 \\
\hline & Office work & 94 & 11 \\
\hline & $\begin{array}{l}\text { Home-centered } \\
\text { work }\end{array}$ & 29 & 3.39 \\
\hline
\end{tabular}


Table 2: Distribution of lice infection variables, history of personal or familial infection

\begin{tabular}{|l|l|r|r}
\hline Variable & & \multicolumn{1}{c|}{ F. } & \multicolumn{1}{c}{$\%$} \\
\hline Lice infection & Yes & 132 & 15.45 \\
\hline \multirow{2}{*}{ Personal history of lice infection } & No & 722 & 84.54 \\
& Yes & 187 & 21.86 \\
\hline \multirow{2}{*}{ Familial history of lice infection } & No & 667 & 78.10 \\
\hline & Yes & 79 & 9.25 \\
\hline & No & 775 & 90.74 \\
\hline
\end{tabular}

As the results showed, from among 854 female students at elementary school, $132(15.45 \%)$ were infected with immature lice. Lice infection was found to be $23.5 \%$ among rural residents, $23.5 \%$ and $22.8 \%$ among students whose parents were, respectively, uneducated or had an elementary school degree. In $20.9 \%$ of cases, the father did labor work. $34.1 \%$ of cases had a history of personal infection. $40.8 \%$ of students were found with a history of lice infection in family. $25 \%$ had no bathroom at home. These all comprised the highest prevalence of the disease. Overall, lice infection showed to be significantly correlated with such factors as nationality, place of residence, parents' education, occupation, personal and familial history of infection $(\mathrm{p}<0.05)$.

Statistical tests showed a significant correlation between students' lice infection and age, as the highest prevalence of infection was found among 8-year-old students $(p<0.001)$. Head lice was significantly correlated with father's occupation, as the highest and lowest rates of prevalence belonged, respectively, to students whose father worked freelance and those whose father had an official job $(\mathrm{p}<0.001)$. A statistically significant correlation was found between students' head lice and father's education. The highest rate of prevalence was $23.7 \%$ among students whose father had an elementary school degree while the lowest prevalence $(4.3 \%)$ was among students whose father had a university degree $(p<0.001)$. The highest rate of prevalence $(19.6 \%)$ was among students whose mother was uneducated while the lowest rate $(5.3 \%)$ belonged to those whose mother had a university degree $(\mathrm{p}<$ 0.001 ). A statistically significant correlation was found between lice infection and mother's occupation. The infection rate was $4 \%$ among students whose mother was a housewife and $9.4 \%$ among those whose mother worked freelance $(p=0.002)$. A statistically significant correlation was found between head lice and having a bathroom at home. The highest rate of infection was found among students who did not have a bathroom at home $(18 \%)$ while the lowest rate of infection was found among those with no bathroom at home $(p<0.05)$.

\section{Discussions and Conclusion}

In the present research, 854 female students were selected through multi-stage randomization from all elementary schools in Jam County, Bushehr province, Iran in 2019. The prevalence of pediculosis infection was found to be $15.45 \%$ among students. Despite advances in healthcare in different societies, lice infection still prevails in developing countries and is considered a major health issue (15). As the related body of literature in Iran shows, head lice infection exists in different parts of the country and according to WHO reports, Iran is among the most infected areas worldwide (16). The prevalence of pediculosis has ever increased since the mid-1960s. Global statistics show the prevalence of pediculosis in France (15\%), Australia (33.7\%), Korea (37.2\%), Spain (3.39\%), Taiwan (40\%), Libya (87.6\%), Lebanon (8\%) and England (28.3\%) (17). Moreover, Eivazi et al. reported the prevalence of pediculosis in female elementary schools in west Guilanto be $24.8 \%$ (18), which is more than the present research. Farzinnia et al. (2005) found the prevalence of head lice among female elementary school students in Qom to be $4.5 \%$ (19). The prevalence of lice infection in Jam County showed an epidemic of the disease, which requires the need for combined and all-inclusive interventions including education for students, families and school staff to find ways to prevent, control and report infected cases and provide the required treatments and environmental rehabilitation. A vast majority of research found a higher prevalence of lice infection among girls than boys (20-22). Among reasons for this mention can be made of girls' longer hair vs. boys' frequent haircuts and regular covering of hair by scarves which hinders the diagnosis and hastens the epidemic (21).

In this research, a statistically significant correlation was found between the prevalence of pediculosis and father's education. Similarly, the present research found a significant correlation between lice infection and parents' higher education $(p<0.001)$. The least state of infection was found in students whose parents had a university degree. Rajabzadeh, Davari, Rafinezhad, Abbaszadeh and Zareban reported a similar finding (14,21-24). Parents' higher education level can affect the quality of life, bringing up children, educating healthy life to children and raising their awareness of preventing and solving health-related problems.

In the present research, a statistically significant correlation was found between mother's occupation and lice infection. Students whose mother worked outside home comprised a high percentage of those infected with lice. In a body of research by Davari, Rajabzadeh and Rafinezhad, mother's occupation and infection showed to be significantly correlated (14, 21-22). However, no such correlation was found in the work of research by Farzinnia and Hosseini (19-20). Proper planning is required in healthcare centers to raise parents' awareness by holding classes, distributing booklets, pamphlets and CDs to significantly raise students and mothers' awareness and prevent pediculosis to a great extent. Besides, as the results showed, there are fewer chances of infection among students whose father had an army job. A statistically significant correlation was found between head lice infection and working freelance $(\mathrm{p}<0.001)$.

Dorudgar et al. reported a significant correlation between head lice infection and father's occupation (25). However, Bayat et al. found no significant correlation between students' infection and father's occupation (26). Similarly, a statistically significant correlation was found in the present research 
between lice infection and having a bathroom at home. In fact, the highest rate of infection was found among students who had no bathroom at home. The results reported by Rafiei and Zareban are consistent with the present findings. As they maintained, the better the heath state, the less the infection. Thus, having a bathroom at home is truly effective in reducing infections and taking bath regularly per week can reduce the rate of the infection to a great extent $(24,27)$

As for age, the chances of infection were found to be the highest among the 12-year-old group. Students at the fourth grade of elementary school were 1.23 times more likely to be infected than others. Yet, this difference was not found to be statistically significant $(\mathrm{p}=0.13)$. Dorudgar et al. (2011) explored factors affecting head lice infection among elementary school students in Aran Bidgol City. They found a higher prevalence of the disease among the third grade students than others. No statistically significant correlation was found between head lice infection, grade of school and age, which is consistent with the present findings (28). Furthermore, Zabihi et al. observed no significant change in head lice infection across age groups and no significant correlation between the prevalence of pediculosis and students' age. Moreover, as the related literature show, the prevalence of lice infection among those above 9 years old is lower than others (17). Younger children's more dependence on mother and adults in showing healthy behaviors such as bathing and combing hair can be among the underlying reasons. The chances of infection among those with no bathroom at home showed to be 2.13 times more than students who had a bathroom at home. No statistically significant correlation was found between lice infection and having a bathroom at home $(p=0.26)$. Thus, regular bathing can prevent or reduce the chances of infection.

\section{Conclusion}

Due to the contagious nature of pediculosis, personal and environmental preventive measures seem essential. Thus, educating students and parents on how the disease is transmitted, the essentiality of using personal stuff, raising parents' awareness of the required healthcare and treatments (haircut, careful use of shampoo, regular examination of hair, visiting the closest local healthcare center to get the shampoo if needed) can be effective in controlling the disease. Moreover, making preventive interventions by the education system can control the disease. Instances are the hiring of health educators in elementary school, education and reeducation of pediculosis prevention and control for teachers and managers, reducing the number of students in class, regular weekly examinations by the health educator and following up infected cases.

\section{Conflict of interests}

None to declare

\section{Acknowledgements}

Hereby, the present authors are grateful to health educators, healthcare staff in Jam County in
Bushehr and all students participating in this research project.

\section{References}

1. Noori A, Ghorban Pour M, Adib M, Noori A.V, Niazi S. Head lice infestation (Pediculosis) and its associated factors in the rural school students of Kalaleh, in the academic year 1392-93 . Hakim Jorjani J. 2015; 2(1): 56-60.

2. Rafiei A, Kasiri H, Mohammadi Z, Haghighizade H $\mathrm{MH}$. Head lice infestation and associated factors in school children in Ahvaz city. Journal of Infectious Diseases and Tropical Medicine, Infectious Diseases Specialist Association.2010:45:41-45

3. Coates SJ, Thomas C, Chosidow O, Engelman D, Chang AY. Ectoparasites: Pediculosis and tungiasis. Journal of the American Academy of Dermatology. 2020 Mar 1;82(3):551-69.

4. Kamiabi F, Nakhaei FH. Prevalence of pediculosis capitis and determination of risk factors in primaryschool children in Kerman. EMHJ - Eastern Mediterranean Health Journal. 2005;11(5-6):988-92(persian)https://apps.who.int/ iris/handle/10665/117030.

5. Bauer E, Jahnke C, Feldmeier H. Seasonal fluctuations of head lice infestation in Germany. Parasitology research. 2009;104(3):677-81.

6. Rafinejad J, Nourollahi A, Biglarian A, Javadian E, Kazemnejad A, Doosti S. The comparison of the effect of permethrin shampoo and lindane lotion on the treatment of head lice (Pediculus Humanus Capitis) in the primary school pupils. Journal of Mazandaran University of Medical Sciences. 2011;21(83):35-41

7. Manrique-Saide P, Pavía-Ruz N, Rodríguez-Buenfil JC, Herrera Herrera R, Gómez-Ruiz P, Pilger D. Prevalence of Pediculosis capitis in children from a rural school in Yucatan, Mexico. Revista do Instituto de Medicina Tropical de São Paulo. 2011;53(6):325-7.

8. Ismail MT, Kabakibi MM, Al-Kafri A. Epidemiology of pediculosis capitis among schoolchildren in Damascus, Syria. Indian Journal of Paediatric Dermatology. 2018;19(4):331

9. Rassami W, Soonwera M. Epidemiology of Pediculosis capitis among schoolchildren in the eastern area of Bangkok, Thailand. Asian Pac J Trop Biomed. 2012;2(11):901-4.

10. Mehr Aghaei. M. Prevalence of head lice infestation and its effective factors in elementary school students in Ahvaz city in winter 2016 and spring 2017. Ahwaz University of Medical Sciences. 2016;101.

11. Moosazadeh M, Afshari M, Keianian H, Nezammahalleh A, Enayati AA. Prevalence of head lice infestation and its associated factors among primary school students in Iran: A systematic review and meta-analysis. Onsog Public Health Res Persepct. 2015;6(6):346-56.

12. Saghafipour A, Akbari A, Norouzi M, Khajat P. The epidemiology of pediculus is humanus capitis infestation and effective factors in elementary 
schools of Qom Province Girls 2010, Qom, Iran. Majallah-i Dānishgāh-i'Ulūm-i Pizishkī-i Qum. 2012;6(3):46-51.

13. Ghaderi R, Eizadpanah AM, Miri MR, Ahmadi M, Taheri N, Hoseinzadeh Chahkandak F. The Prevalence of pediculosis capitis in school students in Birjand. Modern Care Journal (Scientific Quarterly of Birjand Nursing \& Midwifery Faculty). 2010;7(1):49-54.

14. Rajabzade R, Shoraka HM, Arzamani K, Shahiri M, Emami O, Hosseini SH. Epidemiology of Pediculosis capitis infestation and its associated factors in students. J North Khorasan Univ. 2014;6(4):755-67.

15. Sotoudeh A, Ardakani MF, Asadian A, Kasiri N, Ghobadi K. What is the status quo of high-risk behaviors among male adolescents in the South of Iran?: A cross-sectional study in Bandar Bushehr, Iran. International Journal of Ayurvedic Medicine. 2019;10(3):267-72.

16. Morovati Sharif Abadi M, Moghadasi Amiri M, Falah Mehrjordi S, Aghaei A, Zareshahi F, Alizadeh S. Pediculosis Capitis and Its Related Factors among Girl Primary School Students of Meybod, Yazd Province, in 2015-2016. Journal of Health. 2018;8(5):552-60.

17. Zabihi Ali JAr, Rezvani Mohsen, bichani Ali. Evaluation of head lice infestation rate in primary school students in Babol city in 2004-2005. Journal of Babol University of Medical Sciences. 2006;7(4):88-93.

18. Aivazi.A.Epidemiology of Pediculus humanus capitis infestation and effective factors in elementary schools of children, Islam Abad city, Kermanshah province.Tehran:Tarbiat Modarres University. 1986.

19. Farzinnia B HBA, Reis Karami S, Jafari T. Epidemiology of Pediculosis capitis in female primary school pupils Qom. Hormozgan Med J. 2004; 8(2):103.

20. Hosseini SH, Rajabzadeh R, Shoraka V, Avaznia A, Shoraka HR, Prevalence of Pediculosis and its related factors among primary school students in Maneh-va Semelghan district, Journal of North
Khorasan University of Medical Sciences,Spring 2014.

21. Davari B KM, Poormohammdi, Faramarzi Gohar A, Faizei F, Rafat Bakhash S, Ahmadi S. An Epidemiological study of Pediculus capitis in students of Pakdasht county, in autumn of 2013. Pajouhan Scientific Journal. 2013;14(1):57-63.

22. Rafinejad J, Noorollahi A, Javadian A, Kazemnejad A, Shemshad K, Epidemiology of Pediculosis capitis and its related factors in primary school children in Amlash, Guilan province in 2003-2004, Iranian Epidemiology Journal 2006;1:51-63

23. Abbas-zadeh M, Masinaee-Nejad N, Dabirzadeh M, Heidari M, Epidemiology of head lice infestation among girl primary school children in Zabol (2003), The journal of Toloo-e-behdasht 2004;3:10-15.

24. Zareban, M. Abbaszadeh, M. Moodi, H. Mehrjoo Fard, HR. Ghaffari, Evaluating a health- education program in order to reduce infection to Pediculus Humanus Capitis among female elementary students, Journal of Birjand University of Medical Sciences, Spring 2006;13(26):31- 25

25. Doroodgar A, Sadr F, Paksa A, Mahbobe S, Doroodgar M, Sayyah M, et al. The prevalence of pediculosis capitis and relevant factors in primary school students of Kashan, Central Iran. Asian Pac J Trop Dis. 2014;4(6):500-4

26. Bayat S HPR. prevalence of head lice and head fungal infections in primary school students in the Hamadan province 2004-2005. Articles abstract book of sixth national conference and the first regional congress of parasitology and parasitic diseases, Research Institute Vaccine and Serum making of Razi,Karaj. 2008

27. Rafie A, Kasiri H, Mohammadi Z,Haghighizade M, Pediculosis capitis and its associated factors in girl primary school children in Ahvaz City in 2005-2006, Iranian Journal of Infectious Diseases and Tropical Medicine 2009;45:41-5

28. Bukzek A, Markowska-Gosik D, Widomska D, Kawa IM, Pediculosis Capitis among Schoolchildren in Urban and Rural Areas of Eastern Poland, European Journal of Epidemiology 2004;19:491-495. 